\title{
Support Teaching in Schools: Perceptions of Teacher Trainees
}

\author{
Emmanuel Appiah Dankwah $^{1 *}$, Isaac Atuobi Nyarko ${ }^{2}$, Daniel Darkwa Mensah² \\ ${ }^{1}$ Department of Information Communication Technology, Akrokerri College of Education, Kumasi, Ghana \\ ${ }^{2}$ Akrokerri College of Education, Kumasi, Ghana \\ Email: emmanuelappiah2@gmail.com
}

Received: 11 August 2020; Revised: 16 August 2021; Accepted: 17 August 2021

\begin{abstract}
Support Teaching in Schools (STS) is a vital element in any teacher education programme. It is considered the most fundamental way in helping teacher trainees to become effective implementers of the school curriculum. This study sought to ascertain the perception of teacher trainees on the benefits and challenges of the STS program in Akrokerri College of Education. This study used a hybrid research technique to find out about the perception of teacher trainees towards STS. The study data were collected through online questionnaires, and then descriptive statistics and content analysis approach were used to analyze research questions. The main objective of the paper was to examine teacher trainees perception concerning STS; to find out whether the opinion of teacher trainees on STS differ with regards to gender; to ascertain the benefits and of STS to the teacher trainees; and to identify specific challenges of STS during COVID 19 pandemic. In all 235 teacher trainees responded, findings from the study proved that teacher trainees perceived support teaching in school (STS) as beneficial, as it has helped them connect college base training to practical skills and knowledge of the teaching profession. Time wasting due to single bus for conveying students to practice schools; lack of proper orientation; the inability of some link tutors to visit schools; insufficient teaching and learning resources were some of the challenges encountered by teacher trainees. Other challenges emanating from STS as a result of the COVID 19 pandemic were lack of orientation on online STS, poor internet connectivity, inadequate time and the artificial nature of STS.
\end{abstract}

Keywords: support teaching in schools, COVID 19, pandemic, learning resources, hybrid

\section{Introduction}

The pursuit by the people of a particular country for the government to fix the problems of the nation depends on a complete overhaul of its human capacity and this can be achieved through the education of its citizenry. Education is a powerful instrument that brings about changes. Individuals who have gone through some form of knowledge acquisition and skill training, have always been at the pivot in the growth and expansion of their society. The decisive role the teacher plays, as the one who trains these individuals as agents of societal development, is very crucial. The new fouryear Bachelor of Education (B. Ed.) degree program faced out the Diploma in Basic Education (DBE) introduced in 2004 in Colleges of Education in Ghana. A notable feature of the new programme lays emphasis on Support Teaching in Schools (STS). According to Transforming Teacher Education and Learning (T-TEL) (2020) handbook, the teacher trainees now are expected to spend time in partner schools across all 4 years of study rather than just in their third year,

Copyright (C2021 Emmanuel Appiah Dankwah, et al.

DOI: https://doi.org/10.37256/ser.222021581

This is an open-access article distributed under a CC BY license

(Creative Commons Attribution 4.0 International License)

https://creativecommons.org/licenses/by/4.0/ 
as was the case of the Diploma in Basic education. Excerpts from the T-TEL handbook (2020) state that the vision for the four-year B. Ed. degree curriculum is to transform initial teacher education and secure the training of highly qualified, motivated new teachers who are able to inspire their learners to achieve better outcomes. Again the new B. Ed. program introduced in the colleges of education in Ghana, aims at preparing new teachers who are effective, engaging, and fully prepared to teach the basic curriculum and to improve the learning outcomes and life chances of all learners they teach as set out in the National Teacher's Standards (NTS). One of the four main pillars of the curriculum as stated earlier is STS, which lies at the heart of the four-year program. The STS programme is to help teacher trainees apply and develop skills, knowledge and understanding acquired in their college-based training in schools with the support of mentors and link tutors.

Even though the STS programme comes with immense benefits, which is similar to the findings of AduheneChinbuah (2009) and Amakwah et al. (2017). Interaction with teacher trainees during STS supervision revealed inadequate time, poor planning, lack of administrative support, and lack of proper orientation as some challenges they encountered, which is in line with the findings of Amakwah et al. (2017). This paper, therefore, seeks to find out the perception of teacher trainees on the benefits and challenges of STS program in Akrokerri College of Education.

\subsection{Research objectives}

The study was undertaken to find out the perception of teacher trainees on support teaching in-school programs. Specifically, the study was to achieve the following objectives:

1. To examine teacher trainees' perception concerning STS.

2. To find out whether the opinion of teacher trainees on STS differs with regards to gender.

3. To ascertain the benefits of STS to the teacher trainees.

4. To inquire about the challenges faced by teacher trainees during STS.

5. To identify specific challenges of STS during the COVID 19 pandemic.

\subsection{Research questions}

The paper was guided by the following questions:

1. To what extent do the teacher trainees perceive STS as helping them to apply and develop the skills knowledge and understanding acquired in their college-based training?

2. Does the opinion of teacher trainees in the STS program differ in respect to gender?

3. What benefits do teacher trainees gain from the STS program?

4. What are the challenges encountered by teacher trainees with respect to STS?

5. What other challenges emanated from STS organized during COVID 19 pandemic?

\section{Review of related literature}

In Amakwah et al. (2017), a descriptive survey design was employed to find out the perception of pre-service teachers on teaching practice (on-campus) as an initial teacher preparation programme in University of Education, Winneba. A simple random sampling was used to select 226 pre-service teachers from the College of Technology Education, Kumasi for the study. Data for the study were collected using a questionnaire and analysed with both descriptive and inferential statistics. The findings among others revealed that on-campus teaching practice equips entrants with requisite teaching knowledge, skills, experience, efficacy, professional development and support of their learning. Lack of teaching aids, inadequate time, poor planning, lack of administrative support, and lack of proper orientation on the role of on-campus teaching practice were some of the challenges identified. They further argued that in spite of the challenges, the pre-service teachers rated the programme to be good. Finally, they recommended that adequate time and material resources should be provided in addition to effective planning and orientation on the programme.

Gupta and Rakwal (2020), study assessed the perceptions of teacher trainees towards the two-year teacher education programme being run in Jammu (India). The researchers for achieving the objectives of the study developed 
the Teacher Trainees Perceptions Assessment Questionnaire (TTPAQ). The questionnaire consisted of four scales, namely, Duration, Pedagogical Aspects, Curriculum and Innovation. They chose a sample of 200 students enrolled in the two-year B. Ed. and M. Ed. programmes of a private and government college of education for the study. The results of the study showed that the TTPAQ was a reliable and valid instrument for assessing the perceptions of the teacher trainees towards the two-year teacher education programme. The mean scores of the different scales of the TTPAQ were high which indicated that teacher trainees of the B. Ed. and M. Ed. programmes had positive perceptions towards the duration, pedagogical aspects, curriculum and innovativeness of the programme. In their work, no gender differences were observed in the results of the study. Significant differences were observed between the students of private and government colleges and between the teacher trainees of B. Ed. and M. Ed. classes on all the four scales of the TTPAQ.

“"Teacher trainees' perception of their competence” was undertaken by Aduhene-Chinbuah (2009). The researcher reviewed related literature on the topic, using mainly the library. The questionnaire was the instrument used in collecting data. One set of questionnaires was designed and administered to teacher trainees who had completed their one-year teaching practice under mentorship. A random sampling procedure was used to select a sample that comprised 80 teacher trainees. The data obtained were analyzed using descriptive statistics. The main findings were that: (a) Teacher trainees saw themselves as competent after going through the new programme, which was the in-in-out programme at the teacher training college. (b) The development of the teacher must be done in a holistic way, which should include an appropriate balance of general education, academic specialization as well as professional studies. Among the recommendations made was that during the period of mentorship, more subject matter content should be taught at the study cycle meetings. On-campus teaching practice must be effectively done in all subjects.

Nyamota et al. (2018) also reported a study that was carried out on the perceptions of teacher trainers and trainees on the relevance of instructional resources for Creative Arts teacher education curriculum to learners' needs in Kenya. The larger study from which this paper was drawn was on the perceptions of teacher trainers and trainees on the relevance of the Creative Arts teacher education curriculum to learners' and societal needs. This study was guided by structural-functionalism theory. The pragmatic paradigm was adopted in the study. The study used mixed methods research approach. These involved integrating the qualitative and quantitative approaches. Under this design, both the qualitative and quantitative data were collected concurrently, analyzed separately and then merged for interpretation of overall results. This study targeted teacher trainees, trainers and heads of department (HoDs) of Creative Arts drawn from public primary teacher training colleges in the western region of Kenya. Stratified and simple random sampling methods were used to select the sample whereby three hundred and ten participants were selected for the study. These comprised of 270 teacher trainees, 30 teacher trainers (tutors) and 10 HoDs for Creative Arts. The research instruments used were the teacher trainees' questionnaire and the HoDs interview schedule. Data analysis was done by the use of descriptive statistics whereby frequencies and percentages were calculated using the Statistical Package for the Social Sciences (SPSS) software. The results of the study revealed that teacher trainees and trainers perceived resources such as song repertoire and audio-visuals among others as relevant to the learner and societal needs but inadequate. The instructional resources in the colleges were perceived to be inadequate and obsolete. The lack of rooms to accommodate practical teaching using the suggested resources was also of concern. The researchers recommended that colleges should endeavor to provide all the resources suggested in the syllabus and replace those which are obsolete.

Gupta and Gupta (2020), on the other hand, presented a paper on E-Learning in COVID 19 Lockdown (A Case Study of Primary School Students in Moradabad City). The paper sought to analyze the impact of the lockdown enforcement on the Primary school students in the city of Moradabad, Uttar Pradesh and the adoption of e-learning tools and platforms by the schools and students. This research paper is an effort to understand the response of the students from primary classes (1-5) towards the new concept of the online/E-learning process.

Finally, Aboagye et al. (2020) reported a study that explored the challenges students in tertiary institutions have reported facing in online learning in the era of coronavirus pandemic. Using a sample $(\mathrm{n}=141)$, an initial principal component factor analysis was conducted to group the constructs. Eight groups that emerged were social issues, lecturer issues, accessibility issues, learner motivation, academic issues, generic issues, learner intentions, and demographics. Cronbach's alpha was used to determine the reliability of the scales resulting in the deletion of learner motivation. Comparing the means of the factors revealed that the most important challenge for students to study online was accessibility issues. This was followed by social issues, lecturer issues, academic issues, and generic issues. The mean for the individual items in learners' intention to study online showed that students were not ready to study online. A 
Multiple Regression Analysis was further conducted to determine which factors pose the most important challenges to the student's decision to study online. Social issues and lecturer issues were significant. In the final model, only lecturer issues were significant. The study suggested a blended approach where conventional teaching is combined with online teaching should be ushered the learners to complete online learning.

\section{Methodology}

The study adopted a hybrid technique by using (mixed methods research) defined as a procedure for collecting, analyzing and "mixing" both quantitative and qualitative research and methods in a single study to understand a research problem (Creswell, 2012). FoodRisc Resource Centre (n.a) also defines it as a methodology for conducting research that involves collecting, analyzing and integrating quantitative (e.g., experiments, surveys) and qualitative (e.g., focus groups, interviews, content analysis) research. The population for the research was the first and secondyear teacher trainees of Akrokerri College of Education pursuing the new B. Ed. program in the colleges of education in Ghana. Based on the information collated in the $15^{\text {th }}$ and $16^{\text {th }}$ matriculation ceremony handbook, the population for the study numbered 450 and 435 respectively, hence the total population was 885 .

\subsection{Sampling and sampling techniques}

According to Get (2020), for an online survey, a response rate of $20 \%$ is considered as a good response rate, while a $30 \%$ response rate is considered well. Agreeing to Get (2020), a sample size of 235 students representing $27 \%$ of the total population was considered appropriate for the research. Out of the 235-sample size, 156 were males representing $67 \%$ and 78 females representing 33\%. For the present study, the researcher used simple random probability sampling to select a student from each of the ten categorized programmes of study for an interview. The feedback from the students was used to design an electronic questionnaire using Google forms. A non-probability purposive sampling technique was then used to include a fair representation of students from each of the categorized course groups or subject grouping by sending the same link of the questionnaire to their Telegram platform.

\subsection{Tools used}

The instruments used to collect data for the research were interviews through phone calls and online survey. An interview was conducted initially with 10 students through phone calls to solicit information on the perception of the STS programme. Each student was recorded while the interview was ongoing. Each interview lasted for about 15-20 minutes. The content of the feedback from the students was then analysed and used to design a closed and open-ended questionnaire using Google forms. The questionnaire was in five parts. Part one solicited demographic data on teacher trainees, part two was on teacher trainees' perceptions about STS, part three, on the other hand, was a five Likert scale question of benefits on STS with $1=$ Strongly disagree, $2=$ Strongly agree, $3=$ Neutral, $4=$ Agree and five $5=$ Strongly agree. Part four was also a Likert scale similar to part three but solicited views on challenges of STS. The final part was open-ended questions on emanating challenges on STS because of the COVID 19 pandemic. With respect to the reliability of the research questionnaire Joppe (2000), said a research instrument is reliable if the results of a study can be reproduced under a similar methodology. To determine the internal consistencies reliability of the questionnaire, the coefficient alpha was generated at 0.89 for the Likert scale questions in parts three and four, which means that $89 \%$ of the variance in the score is reliable. The validity was found with the index of reliability at $\mathrm{r}_{1 \infty}=\sqrt{r_{1}}$ similarly used in Sarmah and Hazarika (2012) where $r_{1 \infty}$ the index reliability and r1 is the Cronbach coefficient alpha. So, therefore, the index reliability was at 0.94 , this implies that the question measures the true ability of what it is intended for at a rate of 94\%. Moreover, the open-ended questions in the questionnaire produced similar results compared to the initial feedback from the interview in line with Sarmah and Hazarika (2012) which stipulates that a measure should produce similar or the same results consistently if it measures the same thing repeatedly. 


\section{Findings and discussion}

Findings were discussed in line with the research questions formulated above. Descriptive or inferential statistics were used to examine the Research Questions (RQ) one (1) to four (4) while a content analysis approach was used to analyze research question five (5). RQ 1 used a simple frequency and percentage table. In RQ 2, a test of significance of the difference between means and variance (t-Test: Two-Sample Assuming Equal Variances) was run using Microsoft Excel to determine if the viewpoint of STS differs with respect to gender. The t-test was set at an alpha level of 0.05 . On the other hand mean, standard deviation and rank were used to answer RQ 3 and 4. Mean rating was compared with the theoretical mean rating (assuming a normal distribution of responses) of $3(1+2+3+4+5=15 / 5)$ to determine whether respondents agree with the statement on benefits and challenges of STS. A mean of 3.0 and above indicate agreement with the statement while a mean of below indicates disagreement with the statement.

\subsection{Research questions 1}

To what extent do the teacher trainees perceive STS as helping them to apply and develop the skills knowledge and understanding acquired in their college-based training?

Table 1. Rating of STS programme

\begin{tabular}{ccc}
\hline Rating & Frequency & Percentage \\
\hline Very beneficial & 113 & 48.1 \\
Quite beneficial & 64 & 27.2 \\
Beneficial & 50 & 21.3 \\
Not beneficial & 8 & 3.4 \\
Total & 235 & 100 \\
\hline
\end{tabular}

The result as indicated in Table 1 shows that STS as a component of the new four-year B. Ed. programme in colleges of education is indeed beneficial as it helps students teachers apply and develop the skills knowledge and understanding acquired in their college-based training. Almost half of the sample size (113) representing $48.1 \%$ responded very beneficially. $114(48.5 \%)$ saw it as quite beneficial or beneficial. Only eight students representing $3.4 \%$ responded not beneficial. This outcome is in tune with the result from Amakwah et al. (2017) as it emanated in their research paper that the on-campus teaching programme was rated to be good by the pre-service teachers. Their results indicated clearly that majority of the total respondents 112 representing $49.6 \%$ were of the view that the teaching practice programme was good in training and developing teachers.

\subsection{Research questions 2}

Does the opinion of teacher trainees on the STS program differ with respect to gender?

Table 2. Mean standard, deviation and T-test summary of male and female overall opinion on STS programme

\begin{tabular}{cccccccc}
\hline Item & Gender & Observations & Mean & S/D & df & $\mathrm{t}$ & $\mathrm{p}$ value \\
\hline Opinion of STS by gender & Male & 157 & 3.22 & 0.91 & & & 0.58 \\
& Female & 78 & 3.15 & 0.87 & 233 & 1.97 & 0.58 \\
\hline
\end{tabular}


From the results shown in Table 2, the overall opinion of males towards the STS programme $(\mathrm{M}=3.22, \mathrm{SD}=91, \mathrm{n}$ $=157)$ was relatively greater than the overall opinion of females towards STS $(M=3.15, \operatorname{SD}=0.87, \mathrm{n}=78)$. However, a null hypothesis test $\left(\mathrm{H}_{0}\right)$ : There is no significant mean difference between the overall opinion between male and female teacher trainees for research question 2 revealed that there was no statistically difference at $(\mathrm{P}=0.58, \mathrm{p}>0.05$, $\mathrm{df}=159)$ as indicated in Table 2. This shows that both male and female teacher trainees have similar judgments when it comes to the perception of STS. This result is related to Gupta and Rakwal (2020). In their work, no gender differences were observed in the perceptions of teacher trainees towards the two-year teacher education programme being run in Jammu (India).

\subsection{Research questions 3}

What benefits do teacher trainees gain from the STS programme?

Table 3. Mean, standard deviation and rank of benefits of STS

\begin{tabular}{crcccc}
\hline S/N & Benefits of STS & Mean & S/D & Rank & Decision \\
\hline 1 & Connect college base training to real world & 3.69 & 1.05 & $8^{\text {th }}$ & Agree \\
2 & Enlarge knowledge on role and school operation & 3.70 & 0.98 & $6^{\text {th }}$ & Agree \\
3 & Knowledge of School curriculum and other related materials & 3.77 & 1.04 & $4^{\text {th }}$ & Agree \\
4 & Skills to develop good school community relationship & 3.85 & 1.14 & $2^{\text {nd }}$ & Agree \\
5 & Techniques for assessing lesson during and after teaching & 3.74 & 1.15 & $5^{\text {th }}$ & Agree \\
6 & Help to achieve career objective & 3.70 & 1.23 & $6^{\text {th }}$ & Agree \\
7 & Good classroom management skills & 3.90 & 1.2 & $1^{\text {st }}$ & Agree \\
8 & Ability to build teaching portfolio & 3.84 & 1.15 & $3^{\text {rd }}$ & Agree \\
\hline
\end{tabular}

In the result in Table 3, all the eight items scored above the theoretical mean of 3.0, which means all the students' teachers agreed to the fact that STS is of immense benefit to them. Highest ranked mean was 3.90 with S/N 7 that is "Good class management", followed by "skills to develop good school-community relationship" with a 3.85 mean score. "Ability to build teaching portfolio was ranked $3^{\text {rd }}$ with a resultant mean of 3.84. Our prediction for the highest-ranked among the items for benefits of STS would have gone for "connect college-base training to the real world", however, it was surprisingly ranked last with a resultant mean of 3.69. These results are similar to Aboagye et al. 2020, that teaching practice which is similar to STS is beneficial to teacher trainees since it equips them with requisite teaching knowledge, skills, experience, efficacy, professional development and supports their learning. In Aduhene-Chinbuah (2009), teacher trainees saw themselves as competent after going through the new programme, which was the in-and-out programme at the teacher training college which confirms the assertion that STS is beneficial to teacher trainees.

\subsection{Research questions 4}

What are the challenges perceived by teacher trainees with respect to STS?

Results emanating from Table 4 show some interesting results. A mean resultant below 3.0 was deem a disagreement with any of the items relating to challenges of STS. Students' teachers disagreed with the last two ranked as "lack of cooperation between link tutors and mentors" and "inadequate time for STS" with a mean scores of 2.83 and 2.35 respectively as a challenge. This shows that mentors and link tutors get along in the line of duty in supervising teacher trainees and proves that there was adequate time for STS as it is given 48 credits weighing across the four years forming $30 \%$ of their training. Students again disagreed with the fact that mentors refuse live video class recording. On the other hand, "Time wasting due to single bus for conveying students" was ranked as the first challenge with a 
mean score of 3.66, followed by "insufficient teaching and learning resources" and "inability of some link tutors to visit schools" with mean score of 3.46 and 3.23 respectively. "Lack of proper orientation" was the last ranked challenge with a mean score of 3.15. The fallout on this section from this paper is similar to the findings of Amakwah et al. (2017). However, refusal by mentors to allow live class video recording and time-wasting due to single bus for conveying student are the unique challenges that were not found in their paper. In Nyamota et al. (2018), instructional resources in the colleges were perceived to be inadequate and obsolete which could drum well the problem of lack of learning resources in some colleges of education to efficiently equip teacher trainees with the necessary skills.

Table 4. Mean standard deviation and rank of challenges of STS

\begin{tabular}{cccccc}
\hline S/N & Challenges of STS & Mean & S/D & Rank & Decision \\
\hline 1 & Lack of cooperation between link tutors and mentors & 2.83 & 1.26 & $6^{\text {th }}$ & Disagree \\
2 & Time wasting due to single bus for conveying student & 3.66 & 1.31 & $1^{\text {st }}$ & Agree \\
3 & Lack of proper orientation & 3.15 & 1.31 & $4^{\text {th }}$ & Agree \\
4 & Inability of some link tutors to visit schools & 3.23 & 1.25 & $3^{\text {rd }}$ & Agree \\
5 & Inadequate time for STS & 2.35 & 1.28 & $7^{\text {th }}$ & Disagree \\
6 & Insufficient teaching and learning resources & 3.46 & 1.25 & $2^{\text {nd }}$ & Agree \\
7 & Refusal by mentors to allow live class video recording & 2.84 & 1.36 & $5^{\text {th }}$ & Disagree \\
\hline
\end{tabular}

\subsection{Research questions 5}

What other challenges emanated from STS because of COVID 19 pandemic?

Qualitative research using a content analysis approach was used to gather information to answer research question five. Open-ended questions were asked in the online survey to deduce some possible challenges of STS during COVID 19 pandemic. The questions were on:

1. Nature of STS during COVID 19 pandemic.

2. Challenges that emanated as a result of the COVID 19 pandemic.

\subsubsection{Nature of STS during COVID 19 pandemic}

Due to Covid 19 pandemic, the second semester of the 2020/2021 academic year STS was innovatively organized adopting e-learning tools and platforms by the schools and students (Gupta \& Gupta 2020). Videos on specific themes in classroom teaching and learning techniques such as developing a child-friendly classroom; developing and teaching with low-cost materials; girl-child education; inclusion in the classroom; evaluation and assessment were uploaded on Google drive. The link to the videos was sent to teacher trainees and their supervisors on Telegram or WhatsApp for download. Teacher trainees were asked specific questions with respect to the videos on classroom teaching and learning techniques to answer. The feedback was submitted to their supervisors via any convenient electronic medium for evaluation and scoring.

\subsubsection{Challenges emanating from STS as a result of COVID 19 pandemic?}

Although teacher trainees rated the STS as beneficial, the advent of the innovative approach in organizing STS as a result of COVID 19 came with challenges, below are some of the challenges that were enumerated by teacher trainees.

1. Difficulties in accessing videos due to poor internet connectivity.

2. Lack of interest due to the absence of feedback from link tutors.

3. High cost of internet bundles to download videos online.

4. Expensive since videos require bigger megabytes of the bundle for download. 
5. Lack of orientation for the online STS program.

Almost all teacher trainees' concerns revolved around the challenges above with just a few of them complaining about their inability to fully complete the task due to lack of money for internet bundle and faulty phones along the way.

\section{Conclusion and recommendation}

The purpose of this research was to ascertain the perception of teacher trainees on the benefits and challenges of the STS program. Results from this study indicate that teacher trainees, opinion on STS as helping them apply and develop the skills knowledge and understanding acquired in their college-based training was positive. Thus, teacher trainees rated the program as beneficial. Nonetheless, there were some challenges such as time-wasting due to single bus for conveying students, refusal by mentors to allow live class video recording which is unique to this research, as compared to similar works in Amakwah et al. (2017), Aduhene-Chinbuah (2009) and Nyamota et al. (2018). Other challenges also emanated as a result of the COVID 19 pandemic, the number one challenge is in line with Aboagye et al. (2020) assertion that the most important challenge out of the final seven construct deduced in their study for students to study online was accessibility issues. In light of these persons in authority, should provide the needed resources, proper planning and the needed commitment from all and sundry to achieve the success of the programme. The core of the new school standard base curriculum implemented in Ghana is the belief in nurturing creative, innovative, critical thinkers and responsible citizens in the Ghanaian child. In view of this, there is the need for trainer of trainers (colleges of education) to churn out responsible, creative, innovative, self-motivated basic school teachers who can help in the successful implementation of the new standard based curriculum which seeks to shift the structure and content of the education system from merely passing the examination to building character, nurturing values and raising literate who can think critically (NaCCA, 2019).

The following recommendations are made based on the findings:

1. School authorities should liaise with appropriate authorities to secure enough school buses for the STS programme.

2. Teaching and learning materials help learners concretely understand concepts better during teaching and learning. Enough teaching and learning resources should be provided for the smooth running of the programme.

3. STS coordinators should put in place supervisory measures to make sure all link tutors visit partner schools for supervision.

4. Timely and regular orientation should be organized to acquaint students and link tutors with what is expected of them during mentee ship and supervision respectively. Especially new tutors who join the college staff should be properly oriented.

5. Teacher trainees should be assisted with an internet bundle to encourage them to fully participate in online STS should a need arise.

6. A comprehensive e-learning programme should be introduced in the colleges of education curricula to equip students with the necessary skills in teaching and learning using electronic media.

\section{References}

[1] Aboagye, E., Yawson, A. J., \& Appiah, K. N. (2020). COVID-19 and e-learning: the challenges of students in tertiary institutions. Social Education Research, 2(1), 1-8. https://doi.org/10.37256/ser.212021422

[2] Aduhene-Chinbuah, B. (2009). Teacher trainees' perception of their competence: a study of selected seventh day adventist teacher training college trainees, Asokore, Ghana. University of Cape Coast. Institute Of Education. http://hdl.handle.net/123456789/2634

[3] Amakwah, F., Oti-Agen, P., \& Sam, K. F. (2017). Perception of Pre-Service Teachers' Towards the Teaching Practice Programme in College of Technology Education. Journal of Education and Practice, 8(4), 13-20. https:// academic.microsoft.com/paper/2611762120

[4] Creswell, J. (2012). Educational research: Planing, conducting and evaluating quantitative and qualitative research (4th ed.). Upper Saddle River, NJ: Pearson Education. https://www.pearson.com/us/higher-education/ 
product/Creswell-Educational-Research-Planning-Conducting-and-Evaluating-Quantitative-and-Qualitative-Research-4th-Edition/9780131367395.html

[5] FoodRisc Resource Centre. (n.a.). A resource centre for food risk and benefit. http://resourcecentre.foodrisc.org/

[6] Get, V. D. (2020, April 21). How to determine population and survey samples. Market survey. https://www. checkmarket.com/blog/how-to-estimate-your-population-and-survey-sample-size/

[7] Gupta, A., \& Rakwal, R. (2020). A study of the perceptions of teacher trainees towards the two year teacher education programme being run in India. Social Education Research, 1(2), 79-86. https://ojs.wiserpub.com/index.php/ SER/article/view/137

[8] Gupta, P., \& Gupta, P. (2020). E-learning in Covid-19 lockdown (A case study of primary school students in Moradabad city). International Journal in Management and Social Science, 8(5), 12-18. https://www.indianjournals.com/ijor.aspx?target $=$ ijor:ijmss \& volume $=8 \&$ issue $=5 \&$ article $=002$

[9] Joppe, M. (2000, February). The Research Process. http://www.ryerson.ca/ mjoppe/rp.htm

[10] National Council for Curriculum and Assessment (NaCCA). (2019). Teachers resource pack primary 1-6. Ministry of Education, Ghana. https://nacca.gov.gh/wp-content/uploads/2019/06/TEACHER-RESOURCE-PACK-P1-P6.pdf

[11] Nyamota, K. A., Kisilu, A. S., \& Barasa, P. L. (2018). The perceptions of teacher trainers and trainees on the relevance of instructional resources for Creative Arts teacher education curriculum to learners' needs in Kenya. International Journal for Innovation Education and Research, 6(1), 57-73. https://doi.org/10.31686/ijier.vol6.iss1.920

[12] Sarmah, B., \& Hazarika, B. (2012). Determination of reliability and validity measures of a questionnaire. Indian Journal of Education and Information Management, 1(11), 508-517. http://citeseerx.ist.psu.edu/viewdoc/download;jsessionid=94DBB1B74E24F9DEF455C95569967AD3?doi=10.1.1.465.5246\&rep=rep1\&type=pdf

[13] T-TEL Professional Development Programme. (2018). Four-Year Bachelor Of Education Degree Supported Teaching in Schools (School Placement Handbook). Ministry of Education, Ghana. pp. 1-5. https://t-tel.org/download/ doc-45/ 